\title{
Meg Stuart: dançando estados
}

\section{Cláudio Marcelo Carneiro Leão Lacerda*}

Resumo

Este texto objetiva olhar para a obra da coreógrafa contemporânea Meg Stuart e investigar o que faz com que ela seja tão desestabilizadora e provocadora. Essa investigação foi feita pelo viés da teoria da desconstrução de Jacques Derrida e conceitos correlatos, partindo de suas questões filosóficas para poder relacioná-las com os procedimentos criativos, propostascênicas e abordagem de corpoda referida coreógrafa.

\begin{abstract}
This text aims to look at the oeuvre of contemporary choreographer Meg Stuart and investigate what makes it so destabilizing and provocative. This investigation was undertaken from the point of view of the theory of deconstruction by Jacques Derrida and related concepts, departing from his philosophical questions in order to relate them to the mentioned ahoreographer's ereativela procedures, performing proposals and approach to the body.
\end{abstract} PGi Bgdą̣̂a. Desconstrução. critical approach. Lỏndres: Blackwell, 2005 hy. Deconstruction. 
Meg Stuart é uma das mais provocadoras criadoras em dança da contemporaneidade. Escolhemos o viés da teoria da desconstrução de Jacques Derrida para poder tecer relações com e investigar seus procedimentos criativos, propostas cênicas e abordagem de corpo. Stuart não cita explicitamente influências das teorias de Derrida para ativar seu trabalho, mas é notoriamente uma criadora desconstrucionista, com procedimentos e obras muito particulares e idiossincráticas.

Construímos esse artigo de forma que, primeiramente, expomos a teoria da desconstrução de Derrida e conceitos correlatos, relacionando com outros autores como Homi Bhabha e Rudolf Laban; em segundo lugar, discorremos sobre as particularidades do medium da dança; em seguida, tratamos da obra de Stuart, fazendo ligações com a proposta desconstrucionista e examinando como a coreógrafa afeta o medium da dança.

\section{Derrida e a teoria da desconstrução}

As ferramentas conceituais concebidas por Jacques Derrida formam um dos mais importantes arcabouços teóricos da contemporaneidade para pensar toda a construção logocêntrica ocidental. Seja na filosofia, na política, nas artes e em outros campos do conhecimento, oferecem uma ampla gama de aplicação.

Derrida preocupou-se, principalmente, em dissolver polaridades que têm constituído o pensamento e a filosofia ocidentais. Em Força e Significação, Derrida (2008) critica o Estruturalismo e o privilégio que este concede à linguagem para ser um explicador universal dos eventos do mundo, tendo como foco a importância altamente desproporcional conferida à forma em detrimento da força, ou melhor, por separar a forma da força. O procedimento estruturalista para expor esta unidade formal se dá por meio de uma neutralização do conteúdo, a energia viva da significação, a força.

Derrida (2008) propõe uma desconstrução da estrutura, a qual "pode ser metodicamente ameaçada a fim de que possa ser compreendida mais claramente e revelar não apenas seus suportes mas também aquele lugar secreto no qual não é nem construção nem ruína mas labilidade" (p. 5). A desconstrução surge como uma economia que escape a esse sistema de oposições metafísicas -- força-forma, duração-espaço, qualidade-quantidade, profundidade de significação-superfície das figuras, natureza-cultura, presença-representação, significante-significado, dentro-fora, imagem-realidade, corpo-alma --, na qual as diferenças examinadas seriam, simultaneamente, de sítio e de força. Para quebrar essa estrutura de oposições, proceder-se-ia através de uma certa organização, um certo arranjo estratégico, que, dentro do campo da oposição, usa suas forças para virar seus próprios estratagemas contra ele, produzindo uma força de deslocamento, que se espalha através do sistema inteiro, fissurando-o em toda direção e delimitando-o completamente (p. 22). Derrida explica que essa ideia de desconstruir, de descentrar, de pensar a estruturalidade da estrutura, não surgiu de um único evento, uma única dou- 
trina ou um único autor; ela é parte da totalidade de uma era, a nossa.

O espaço de tensão entre polaridades precisa ser habitado, diz Derrida (2006, p. 66) em Lingüística e Gramatologia. Um espaço de adiamento, de labilidade, de desestabilização, de devir, que não é valorizado pela filosofia e pela cultura ocidentais, justamente porque estas têm se baseado nessas polaridades - a escuridão (auto-esconder-se) e a luz (auto-revelar-se), mesmo antes de Platão - para se produzir.

Um dos elementos importantes para habitar esse espaço é o conceito de rastro. Derrida nega que haja uma presença absoluta. Para ele,

uma lacuna intransponível existe entre ter um pensamento e regis trá-lo e entre experienciar um sentimento e sabê-lo. O pensamento real (sentimento) já está desaparecendo enquanto é registrado; as sim, seu registro pode ser imperfeito ou incompleto. (SCHROEDER, 2005, p. 281)

Então, o que percebemos é o rastro, que é o próprio significante, o que é acessível da realidade. "A desconstrução da presença passa pela da consciência, logo, pela noção irredutível do rastro" (DERRIDA, 2006, p. 86). O conceito de arqui-rastro arranca o conceito de rastro ao esquema clássico que faria derivar de uma presença ou de um não rastro originário.

O rastro não é somente a desaparição da origem, ele quer dizer aqui - no discurso que proferimos e segundo o percurso que seguimos - que a origem não desapareceu sequer, que ela jamais foi retroconstituída a não ser por uma não-origem, o rastro, que se torna, assim, a origem da origem. [...] a não-apresentação ou a des -apresentação é tão "originária" como a apresentação (ibid., p. 76)

O rastro é verdadeiramente a origem absoluta de sentido em geral. O que vem afirmar mais uma vez, que não há origem absoluta do sentido em geral. O rastro é a diferência que abre o aparecer e a significação. Articulando o vivo sobre o não-vivo em geral, origem de toda repetição, origem da idealidade, ele não é mais ideal que real, não mais inteligível que sensível, não mais uma significação transparente que uma energia opaca e nenhum conceito da metafísica pode descrevê-lo. (ibid., p. 80)

Desfazer a ideia de origem, ideia fundamental para uma onto-teologia, implica em desfazer a ideia de passado absoluto. Mais ainda, a ideia de passado, presente e futuro é dissolvida, pois o tempo é considerado uma passividade fundamental: "Os conceitos de presente, de passado e de futuro, tudo o que nos conceitos de tempo e de história deles supõe a evidência clássica -- o conceito metafísico de tempo em geral - não pode descrever adequadamente a estrutura do rastro" (ibid., p. 82). Derrida diz que os filósofos 
frequentemente se enganam porque eles tomam o presente como anterior à rede encoberta que o faz possível (SCHROEDER, 2005, p. 285).

Outro conceito para habitar esse espaço é o de espaçamento, que relaciona-se a pausa, branco, pontuação, intervalo em geral, etc. São espaços de devir, de formação da significação.

O espaçamento (notar-se-á que esta palavra afirma articulação do espaço e do tempo, o vir-a-ser-espaço do tempo e o vir-a-ser-tempo do espaço) é sempre o não-percebido, o não-presente e o não-cons ciente. (DERRIDA, 2006, p. 83)

[...] o espaçamento como escritura é o vir-a-ser ausente e o vir-a-ser inconsciente do sujeito. Pelo movimento de sua deriva, a emancipação do sujeito retro-constitui o desejo da presença. [...] E a ausência original do sujeito da escritura é também a da coisa ou do referente. (ibid. p. 84)

Já o conceito de diferência [differance] baseia-se em uma "proliferação interminável de contrastes que multiplicam significações" (SCHROEDER, 2005, p. 284). A diferência age numa dimensão temporal e numa dimensão espacial. Na primeira, a significação é adiada até que o próximo elemento na série emirja (entretanto, a série nunca termina); na segunda, produz novas possibilidades de significação, contrastando termos uns com os outros. A diferência dissolve as polaridades, pois não é nem uma origem nem um resultado, é tanto ativa quanto passiva, tanto produto quanto produção; também quebra o fundamento cartesiano principal, a separação corpo/mente, pois descreve o funcionamento dos processos mental e físico. Derrida acrescenta que o número de termos que afetam a identidade de qualquer termo individualmente está em constante proliferação, nunca fixo, acarretando a noção de que "o significado de todo termo está constantemente sob revisão" (ibid.).

A metafísica da presença, o logocentrismo, as ideias de estrutura, origem, passado absoluto, verdade, significado transcendental, todos eles, para funcionar, exigem um centro, uma presença central. O grande golpe desconstrutivista é a noção de que esse centro não existe; ele é faltante.

A estrutura - ou antes, a estruturalidade da estrutura - apesar de ter estado sempre funcionando, tem sempre sido neutralizada ou reduzida, e isto por um processo de dar-lhe um centro ou de referir-lhe a um ponto de presença, uma origem fixa. A função des te centro foi não apenas orientar, equilibrar e organizar a estrutura -- não se pode de fato conceber uma estrutura sem organização -- mas, acima de tudo, certificar que o princípio organizador da estrutura limitaria o que poderíamos chamar de jogo da estrutura. Orientando e organizando a coerência do sistema, o centro de uma estrutura permite o jogo de seus elementos dentro da forma total. 
E até hoje a noção de uma estrutura da qual falta um centro representa o próprio impensável (DERRIDA, 2008, p. 352).

Barthes (apud PERRONE-MOISÉS, 2005, p. 98) afirmou que "descrever sistemas significantes postulando um significado último é tomar partido contra a própria natureza do sentido". A noção derridiana de centro faltante ataca de frente o significado último.

Entretanto, para compensar esse centro faltante, esse não lugar [nonlocus], a estrutura terá que se valer da violência de uma verdade para se impor. Esse centro, então, vai receber, sucessiva e regularmente, diferentes formas e nomes, em uma série de substituições de centro para centro.

Fizemos uma ligação desses conceitos de Derrida com as ideias de Homi Bhabha (1998) de "momento de trânsito", "sensação de desorientação", "emergência dos interstícios", "temporalidade intervalar", "entre-lugar", as quais, entre outras, evocam esse lugar do entre, das lacunas, dos vãos, lugares onde novas significações surgem e se transformam na condição de vários "pós-" da contemporaneidade. Propomos que é nesses espaços que as criações de Meg Stuart transitam.

O trabalho fronteiriço da cultura exige um encontro com "o novo" que não seja parte do continuum de passado e presente. Ele cria uma ideia do novo como ato insurgente de tradução cultural. Essa arte não apenas retoma o passado como causa social ou preceden te estético; ela renova o passado refigurando-o como um "entre-lugar" contingente, que inova e interrompe a atuação do presente. O "passado-presente" torna-se parte da necessidade, e não da nostalgia, de viver (BHABHA, 1998, p. 27).

O trabalho de Stuart é fronteiriço porque habita essa tensão entre polaridades (Derrida), esse entre-lugar (Bhabha).

Derrida (2006, p. 88) ainda comenta sobre os "significantes acústicos", que equivalem a um conceito linearista de tempo, unidimensional, que corresponde ao conceito de signo que permanece inserido na história da ontologia clássica, a relação biunívoca entre face significante e face significada. Ciane Fernandes (2007) relaciona três maneiras nas quais se lida com o tempo na produção de significações:

a) o tempo linear -- correspondente ao mencionado acima por Derrida --, que liga passado-presente-futuro, numa configuração teleológica, 0 futuro como um alvo a ser conseguido, através de uma progressão;

b) o tempo circular, que evoca tradições por meio da repetição, revivendo e reproduzindo eventos, pensamentos, mitos, um tempo que foca no passado;

c) o tempo tridimensional, representado na figura do Anel (ou Fita) de Moebius, onde polaridades se confundem, onde o dentro converte-se em fora e vice-versa e, consequentemente, onde relações biunívocas se desestruturam (ou se pulverizam): o passado torna-se presente, que torna-se futuro, 
que está adjacente/sobreposto a passado, onde força se encadeia junto a forma.

O Anel de Moebius é o próprio espaço entre polaridades, onde as significações se pulverizam, não são estanques e são dinâmicas. Fernandes (2007) utiliza esta figura para falar sobre o legado de Rudolf Laban e também para pensar o procedimento coreográfico de Pina Bausch. Aqui, afirmamos que o trabalho de Stuart também habita esta relação do Anel de Moebius. "A identidade a si do significado se esquiva e se desloca incessantemente" (DERRIDA, 2006, p. 60).

\section{Sobre o medium da dança}

O medium da dança é formado pelas interrelações, ou nexo, entre os componentes Movimento, Dançarino(a)/Performer, Espaço/Ambiente Visual e Elementos Sonoros, conforme Janet Adshead e Valerie Preston-Dunlop.

São as relações entre os componentes que formam a estrutura, daí o movimento e outros elementos de natureza visual e sonora serem manipulados e colocados juntos em maneiras particulares para criar uma forma. Especificamente, as relações são criadas pelo movimento no tempo e espaço em associação com materiais visuais e sonoros. (ADSHEAD, 1988, p. 41)

O nexo é a rede invisível de conexões que mantém a obra una. Ele representa incontáveis decisões artísticas que nascem da visão de mundo em geral do artista e sua visão do lugar da dança dentro dele. (PRESTON-DUNLOP, 1998, p. 4)

Primeiramente, é importante considerar a natureza de multicamadas e multissensorial da dança. Preston-Dunlop aponta que "uma apresentação de dança não comunica diretamente, mas contém camadas de elementos significantes criados pelos vários participantes no evento, incluindo o espectador" (1998, p. 7). Camadas que são feitas de símbolos discursivos e afetivos, segundo Ramsay Burt (1995). José Gil, por sua vez, profere que "uma coreografia comporta múltiplos estratos de tempo e de espaço" (2004, p. 71). Fernandes aponta que "[n]a cadeia significante, os movimentos da dança necessariamente multiplicam suas possibilidades de interpretação, ao invés de conceberem uma clara mensagem ou significado." (2007, p. 58). Quanto à multissensorialidade, vários são os canais de percepção e sensação, ativados na apreciação de uma dança: cinestésicos, visuais, auditivos (LACERDA, 2010, p. 74).

Em segundo lugar, tanto Preston-Dunlop (1998) quanto Anna Sanchez-Colberg (1996) consideram que, num corpo dançando, estão em operação tanto discursos - aqui se entende discursos como sistemas de relações - 
semióticos quanto fenomenológicos. Lá estão signos presentes na interação humana, que incorporam pensamentos e sentimentos, signos como "agentes externos internalizados, impingindo no corpo" (SANCHEZ-COLBERG, 1996, p. 46), "incorporados" (FOUCAULT, 1988). Estes formam a instância semiótica. Elementos dessa instância podem ser mais fáceis de identificar no corpo cotidiano ou "corpo comum", nos quais os "movimentos finalizados falam a língua clara das funções sociais" (GIL, 2004, p. 75), no corpo do ator de teatro, cujos gestos e cujas palavras "reconstroem o espaço e o mundo" (ibid., p. 14), e em danças narrativas extremamente codificadas (por exemplo, as danças clássicas indianas).

Estes elementos estão em interrelação com a experiência fenomenal do corpo em dança, no aqui-e-agora, no espaço e no tempo experienciados, seguindo necessidades inerentemente físicas, aspectos da experiência em não significação, como movimentar-se, respirar, comer, suar, cansar-se, e também a fenomenalidade desse corpo em sua espacialidade própria (incluindo espaço interno), sua relação com o espaço circundante, a experiência em si, por exemplo, de uma transferência de peso. Trata-se da instância fenomenológica, que contém elementos ou pré linguísticos ou que ultrapassam as significações estruturadas ou mediadas pela linguagem e estão primariamente calcados na experiência.

Gil diz: "há duas espécies de equilíbrio corporal: o puramente mecânico, de um sistema físico; e um outro que o movimento e a consciência introduzem no corpo. O movimento dançado nasce da colaboração destes dois equilíbrios" (2004, p. 17). O grau de modulação e também o grau de visibilidade entre as instâncias semiótica e fenomenológica irão variar de acordo com gêneros e estilos de dança, em diferentes épocas e contextos e também entre diferentes criadores.

Para não corrermos o risco de polarizar essas instâncias em extremos, de um lado, um corpo semiotizável, do lado do signo e da linguagem verbal, e, de outro, um corpo incodificável, singular, exprimindo uma experiência indizível, seria interessante e saudável levar em consideração a proposta de Gil de um corpo paradoxal:

Consideramos aqui o corpo já não como um "fenômeno", um percebido concreto, visível, evoluindo no espaço cartesiano objetivo, mas como um corpo metafenômeno, visível e virtual ao mesmo tempo, feixe de forças e transformador de espaço e de tempo, emissor de signos e transsemiótico, comportando um interior ao mesmo tempo orgânico e pronto a dissolver-se ao subir à superfície. Um corpo habitado por, e habitando, outros corpos e outros espíritos e existindo ao mesmo tempo na abertura permanente ao mundo por intermédio da linguagem e do contato sensível, e no recolhimento da sua singularidade, através do silêncio e da não-inscrição. (ibid., p. 56) 
Muitas visões baseadas em opostos, ainda hoje, pautam o que se entende, se faz e se fala sobre dança, principalmente quando esta é confrontada com o teatro, trazendo oposições como: dança e teatro; dançarinos e atores; movimento e palavra; espontaneidade e representação; feminino e masculino.

Há ainda a tendência de se considerar atores como os intelectuais do palco, e dançarinos como seres espontâneos capazes de entrar em contato com as forças escondidas do universo. Nossas mentes ainda se apegam à ideia de que dentro de cada homem há uma divisão entre mente e corpo. Corpo/mente, coração/cabeça -- nes sas construções binárias nós mais uma vez encontramos a dicotomia básica do masculino/feminino. (KERKHOVEN apud FERNANDES, 2007, p. 27)

Pensar em termos de polaridades pode levar a uma tendência a se pensar em fatos consumados, estados rígidos, em detrimento à qualidade de transformação permanente da dança: "A explicação do mundo das formas de dança não deve ser confinado à enumeração de estados rígidos. Este mundo deve ser considerado como ondulações (transformações) vivas em constante mudança" (LABAN in BARTENIEFF apud FERNANDES, 2007, p. 36). Fernandes explica que:

para alcançar tal noção "dinâmica", [Rudolf] Laban baseou suas teorias de movimento num "continuum entre polaridades", como mobilidade e estabilidade, e interno e externo. Como na simbólica correspondência entre sentimento e forma, movimento e notação, corpo e mente, tais polaridades se relacionam dentro de um todo unificador (FERNANDES, 2007, p. 36).

O fato de Laban considerar a relação entre dois opostos como um processo transformativo, num "continuum de re-definições e buscas" (FERNANDES, 2007, p. 36) nos faz conectá-lo aos pensamentos de Derrida sobre ocupar os espaços entre as polaridades.

Meg Stuart e a companhia Damaged Goods: dançando estados

Meg Stuart desenvolve seus projetos criativos em sua companhia Damaged Goods, atualmente baseada em Bruxelas, Bélgica. Stuart é norte americana, mas seu trabalho teve maior repercussão na Europa. É um tanto nômade, passando alguns anos em cidades europeias (Bruxelas, Berlin, Zurich) que lhe dão patrocínio para desenvolver seus trabalhos, mudando-se, em seguida.

Podemos dizer que esse nomadismo reflete-se em seu trabalho, tendo a exploração da diferença como uma característica muito forte, repercutindo nos seguintes aspectos: 
a) a variação de modos de apresentação, passando pela dança, instalação e performance, e a variação dos elementos utilizados (vídeo, texto, ambientação); acontecem tanto ao longo de um trabalho específico, como em Appetite (1998), quanto entre obras diferentes;

b) a bagagem diversa dos colaboradores (dançarinos, atores, artistas visuais e de vídeo, designers, músicos e teóricos);

c) as participações dos colaboradores, seguindo essa qualidade nômade, na medida em que alguns contribuem intensamente para um determinado projeto, porém, em um projeto seguinte, outras ideias pedem outros elementos e outros colaboradores;

d) a diversidade dos dançarinos e atores, com tipos de corpos, procedências e formações em dança diversas;

e) a identidade própria de cada espetáculo: como cada trabalho inicia de uma proposta e/ou colaborações diferentes, cada um termina tendo uma "cara" bem diferente da do outro.

Para uma artista da dança que se vê, como Stuart se viu, num ambiente saturado pelo legado do meio da dança -- técnicas e convenções e as contribuições vanguardistas que as reviram -- e no ambiente saturado da sociedade contemporânea -- velocidade nos trânsitos (literais e metafóricos), saturação visual e sonora, apelo ao consumo excessivo como motor de comportamento, liquidificação de verdades, poderes e discursos --, como encontrar a sua voz, ou melhor, a sua dança?

No caso de Stuart, como ressignificar seu corpo dançante, formado pela New York University, nas tradições da dança moderna e contemporânea americanas, tendo alcançado uma excelência técnica e dançado na companhia de Randy Warshaw (ex membro da companhia de Trisha Brown)? Stuart procurou práticas que lhe dessem uma "clareza na dança" (STUART apud PEETERS, 2010, p. 15), como a técnica de Alexander, a Improvisação de Contato, a técnica de release de Skinner e a técnica de Klein. Ao mesmo tempo, ela se perguntava como dar atenção ao "barulho interno" que ela experimentava, "como traduzir essas sensações e esses monólogos internos em movimento?" (p. 15). Ao mesmo tempo tendo uma profunda confiança na inteligência do corpo, também o reconhece como um "corpo discordante" (p. 15), cujas partes podem estar sentindo e querendo dizer desejos e coisas diversas umas das outras.

O potencial do movimento corporal de carregar significações é um grande manancial para Stuart. Entretanto, como sabemos, as significações, especialmente na sociedade ocidental, logocêntrica e falocrática, têm como gerenciador o discurso, falado e escrito. Anteriormente a Stuart, praticamente todos os vanguardistas teatrais e da dança, ao longo do séc. XX, desenvolveram uma desconfiança na linguagem falada/escrita como explicador das vivências humanas (SAŅCHEZ-COLBERG, 1996). Também, Derrida, como visto anteriormente, criticou o Estruturalismo, justamente pelo privilégio concedido por este à linguagem para ser um explicador universal dos eventos do mundo. O corpo tem maneiras próprias de passar informações, que incluem conteúdos pré e não verbais, além dos verbais. O foco de investigação de 
Stuart mantém-se nessas informações/desejos desse corpo inteligente/desejante/discordante, cujas manifestações quase sempre estão encobertas pela vivência do dia a dia e pelas convenções sociais. Em suas palavras,

[...] o corpo tem uma inteligência própria e uma maneira de digerir situações complexas que a linguagem falada não pode tocar. (STU ART apud PEETERS, 2010, p. 25)

Eu poderia dizer que, para mim, todo movimento expressa desejo. Não simplesmente o desejo físico ou erótico, ou o desejo material de querer, possuir ou habitar algo, mas o desejo de fazer contato, de se anunciar, de expor a si mesmo ao espectador e ao outro no palco. Consequentemente, todo movimento também expressa e incorpora a comunicação faltante, que falha, o censurado e todas as condições, reais ou projetadas, que bloqueiam o acontecimento de qualquer ação ou conexão. Talvez, todas as razões pelas quais alguém não consegue lidar efetivamente, em uma dada situação. Frequentemente, minhas coreografias são construídas a partir de tarefas impossíveis, como a vontade de comprimir o tempo, de reescrever a própria história, de viver em vários corpos ao mesmo tempo, de experienciar integralmente a dor de outra pessoa, de abraçar o vazio, de mostrar todas as perspectivas de uma situação complexa em um simples gesto. A coreografia revela a determinação, a falha e a vulnerabilidade da tentativa, ao mesmo tempo. (p. 17) ${ }^{1}$

Desejo está ligado a forças, "a energia viva da significação" (DERRIDA, 2008). Forças têm a ver com dinâmica, tanto visível quanto subterrânea. Stuart pretende ocupar o espaço de tensão entre polaridades -- de um lado, a significação imposta pela linguagem falada/escrita e, de outro, as possibilidades de significação trazidas pelo corpo e não incluídas na linguagem falada/ escrita -- por uma via possível: as forças, que movem o desejo e são movidas por ele e que, às vezes, encontram fruição e, em outras, bloqueios, que vão interferir na relação da pessoa/agente com o mundo e com os outros.

O corpo é o ponto de partida e o laboratório de Stuart, "uma entidade física" (AYERS, 1999, p. 9). O caminho trilhado por Stuart para conhecer e poder trabalhar com essas forças é o autoconhecimento: do corpo, de seus desejos, do que os bloqueia, dos seus medos, das relações com o outro. Tudo através do corpo e do movimento, processo vivido por ela e por todos os dançarinos/atores com as quais ela trabalhou/trabalha. Mais do que terapêutico, esse autoconhecimento vai ser matéria prima para suas danças. Sua metodologia são perguntas, artifício utilizado também por outros coreógrafos como Pina Bausch ${ }^{2}$ e William Forsythe ${ }^{3}$, cada um abordando-o diferentemen-

Pina Bausch (1940-2009), bailarina e coreógrafa alemã, um dos expoentes da dança-teatro, dirigiu a companhia alemã Wuppertal Tanzteather desde 1973 até a sua morte.

3 William Forsythe (1949-), bailarino e coreógrafo norte americano radicado na Alemanha, ganhou notorie- 
te. Perguntas ao corpo são o recurso para habitar aquele espaço entre polaridades. Stuart revela alguns de seus procedimentos, enquanto fala sobre o processo de Disfigure Study (1991):

Como eu me percebo? Como sou olhada como mulher? Como as pessoas veem o meu corpo? (...) O processo de Disfigure Study foi sobre fazer perguntas. Do que se precisa para se definir uma dança ou uma parte da dança ou uma ideia coreográfica? Qual a natureza de uma ideia? Eu posso apenas dançar com a cabeça de alguém? Isso é o bastante? Isto pode ser dança? O que se precisa fazer? Quanto é preciso para fazer uma dança física? Eu tive essas imagens, como "se você me amasse muito, você beijaria meus pés". Isto é uma dança? O que é uma dança? Pode-se fazer uma dança com uma cabeça e dois pés que ressoam e têm significado? Eu poderia iniciar o movimento com qualquer parte do corpo, mas como ir na sua profundidade, como concentrar nela para que exista uma narrativa, para que não seja apenas eu, me deslocando dentro do meu corpo? Como isolar o olho, tentando ser tão específica e clara e "despojada" quanto possível? Quão direto pode-se ser, quão perto do osso? Quanto preciso fazer para dançar, e quão pessoal e próximo eu posso ir? Quão exposta? Como se pode decompor esse sentimento de que estou mostrando a você o que posso fazer? (STUART apud PEETERS, 2010, p. 19)

Para fazer essas perguntas, Stuart propõe olhar atentamente os estados corporais e neles provocar mudanças. "Minha pesquisa com estados originou-se a partir de uma vontade de mostrar um corpo incerto, que é vulnerável e que se questiona" (p. 21). Partindo da ideia de que estamos sempre em um estado, ela propõe uma aguda auto observação nas mais variadas situações, inclusive situações de performance, mas também utilizar artifícios para provocar estados diferenciados, que não acontecem com tanta frequência nas situações cotidianas, para um aprofundamento desse auto conhecimento e consequente produção de possibilidades de criação em dança. A proposta para seus performers, incluindo ela própria, é ter vontade de entrar em lugares instáveis, expandindo suas possibilidades para fora de suas zonas de conforto. "Meu trabalho é sobre transformar as fraquezas em estratégias" (p. 29).

Quanto ao material de movimento, Stuart revela que não está interessada em criar um vocabulário-assinatura, pela qual seja conhecida e que se repita em suas obras. A cada nova criação, uma nova pesquisa é feita e um vocabulário criado especificamente para cada obra: 
Para cada peça criamos uma linguagem específica que informa toda a estrutura e faz com que cada obra pareça muito diferente. Vocabulário, para mim, não está relacionado a estabelecer minha própria linguagem codificada ou estilo; é sobre estar aberta a um novo modo de expressão a cada vez. (STUART apud PEETERS, 2010, p. 26)

Assim como Forsythe foi acumulando um manancial de exercícios de improvisação para trabalhar com os dançarinos ${ }^{4}$, Stuart foi formando uma extensa lista de exercícios que promovem um contato imediato com um estranhamento, através da exploração da desorientação e de mudanças de estado. Para exemplificar, seguem alguns títulos desses exercícios: "Olhando para o seu próprio corpo como se você estivesse morto", "Tarefas impossíveis", "Transformação", "Morfoseando" ["Morphing"], dentre vários outros (PEETERS, 2010). Segundo Ayers (1999), seu interesse na decupagem e desconstrução do corpo faz com que, no ato da apresentação, a qualidade tátil esteja muito presente.

Na visão de Susanne Schlicher (2001, p. 34), Stuart representa a artista obsessiva, atacando, através de sua pesquisa de movimento, as convenções de normalidade/anormalidade em um nível psico-físico, revelando a vulnerabilidade do corpo deformado e defeituoso. Esta fascinação pelo corpo deformado, com movimentos deformados, revelam uma afinidade com artistas plásticos como Francis Bacon. Para Stuart, a deformação funciona como uma metáfora para sua percepção e experiência do mundo. Sugerimos que é um espaço de diferência que esta coreógrafa faz funcionar.

Essa escolha de abordagem corporal e de temática era muito provocativa para os EUA, opina Schlicher (2001), e, por isso, seu trabalho parece pertencer mais à Europa, ao mundo ocidental onde por séculos a imagem de corpos desfigurados tem se inscrito nas memórias coletivas.

Stuart observa, fragmenta e transforma formas e movimentos corporais. Ela busca os defeitos do corpo, as articulações histéricas e narcisistas do corpo humano, a escondida estrutura psicológica da deformação anatômica. Interessa-se por e explora a falha da comunicação humana. Seus corpos são geralmente envolvidos em ações repetitivas e isoladas, com movimentos maníacos, e estados de exaustão depressiva. Gradualmente, essa carga física da movimentação foi caminhando para uma direção em que, mais e mais, se vê menos e menos dança, em sua forma mais facilmente reconhecível. Segundo Schlicher (2001), a colaboração com artistas visuais levou Stuart a minimalizar e reduzir ainda mais seu vocabulário de movimento, examinando cada gesto. Disfigure Study foi o primeiro trabalho que lhe deu um reconhecimento grande. Teve como ponto de partida a dissolução da figura humana que Francis Bacon desenvolveu em suas pinturas. Esta obra possui versões em trio e em solo. Tendo assistido a Disfigure Study em versão solo, com a própria Stuart dançando, pudemos perceber uma qualidade corporal de descentramento,

$4 \quad$ Também realizamos uma pesquisa sobre o processo de trabalho de Forsythe, dentro da pesquisa Dança e Desconstrução, realizada na Universidade Federal de Pernambuco (2010-2013). Ainda não publicada. 
desarranjamento e dissolvimento do corpo, que desafiam a ideia de um corpo uno, sensual, ou de um corpo-objeto, principalmente em se tratando do corpo de uma mulher, semidesnudo, atlético e desejável, exposto em cena.

Em Soft Wear (2000), Stuart passa por poses e flashes, inicialmente percebidos como do cotidiano -- um cruzar de braços, um coçar de cabeça, uma transferência de peso de uma perna para outra, etc. -- e repete-os em estados corporais diferenciados, que sugerem uma dissolução e um desconforto oriundos de um aprisionamento no próprio corpo, que faz com que se olhe para este com uma outra disposição, na qual o estranhamento ocupa uma grande parte.

Stuart (apud PEETERS, 2010, p. 150) diz que "dança é um lugar para tentar coisas com as quais você não está necessariamente confortável". Trabalhando nesse entre-lugar, Stuart e seus dançarinos tentam rearranjar experiências e legados do meio da dança em si, experiências de viver na contemporaneidade e experiências de estados corporais diferenciados. No comentário de Fernandes e Moura (2004) sobre o espetáculo Visitors Only (2003) podemos vislumbrar como essas diversas instâncias de experiência compõem a cena:

Residindo numa zona limítrofe, Visitors Only, com o grupo Damaged Goods, sob a direção de Meg Stuart, articula linguagens como teatro, dança e música. Há uma série de pequenas narrativas, muitas vezes simultâneas que acontecem numa casa "estripada", isto é, uma casa rasgada em corte horizontal, que ocupa toda a extensão do palco, em dois pavimentos, com portas, janelas e passagens estranhas e não ergonomicamente pensadas para seres humanos.... pelo menos não para "normais". Este espaço anormal se relaciona intensamente com seres, aparentemente normais, mas esquizo-mecanicamente alterados pelos processos de modernização, pela tecnologia, pela sede de sucesso, pela perda da doçura, da espontaneidade, que assola e coloniza corpos. Isto está explícito no embate constante entre corpo mecânico-newtoniano e corpo organo-quântico. (FERNANDES e MOURA, 2004)

Uma cena em particular, com os dançarinos em estado de tremor, atinge cinestesicamente o espectador. Stuart (apud PEETERS, 2010) relata que ela e seus dançarinos fizeram um workshop específico para essa técnica de tremor, que leva a um estado de transe e meditação.

Violet (2012) é todo estruturado em mudanças de estados corporais, individuais e coletivos, que necessitam de um tempo estendido para se desenrolar. Aos espectadores, só resta testemunhar o surgimento, desenvolvimento e transformação desses estados, o que muitas vezes podem provocar desconforto e também sonolência, por um lado, e perplexidade, por outro. $O$ acompanhamento sonoro, feito por um músico/programador eletrônico, oferece uma esteira de sons que ora acompanham e enfatizam, ora contrastam com o desenrolar desses estados. Um clima algo opressivo permanece no ar, como se estivéssemos presenciando a fase posterior, ou a sobrevivência, a uma catástrofe. Nesse espetáculo, possíveis significados podem até ter a iminência de surgir, porém se esquivam e se deslocam quando um novo estado corporal começa a ser ativado. 
Em sua maneira idiossincrática, Stuart desafia o próprio medium da dança, acolhendo e utilizando procedimentos e elementos de outras disciplinas, como as artes visuais, o vídeo e arte da performance. As diferentes categorias de colaboradores, mencionadas anteriormente, revela esse interesse. Em Are We Here Yet? (2010), livro editado por Jeroen Peeters, Stuart e seus colaboradores dão seus testemunhos sobre o impacto das obras e processos em seus próprios corpos. O fato de todos efetivamente passarem por uma experiência corporal dá uma qualidade diferenciada nos produtos resultantes. Percebemos que o corpo funciona como o elemento de espaço entre polaridades, se considerarmos que as diferentes áreas artísticas e/ou do conhecimento geralmente configuram-se -- são olhados e considerados pela maior parte da academia e dos órgãos de fomento, por exemplo -- como polaridades entre si.

Quanto aos espaços de apresentação utilizados por Stuart, estes podem variar, indo de um espaço teatral mais convencional até espaços bem diferenciados. Consequentemente, a relação com os espectadores é sempre alterada. Mesmo os espaços mais convencionais, dependendo do colaborador artista visual ou de vídeo em questão, podem receber um tratamento diferenciado. Podem estar recobertos de argila úmida, que, ao desenrolar do espetáculo, vai endurecendo e partindo, como em Appetite. Pode estar forrado de peles. Pode estar repleto de telas de vídeo, como em Splayed Mind Out (1997). Pode ter o cenário de uma sala, dentro de uma estrutura giratória grande que o faz girar com os dançarinos dentro, como em Replacement (2006). Pode abrigar o cenário de um apartamento muito estranho, como em Visitors Only. Pode ser este mesmo cenário num espaço de rua, como em Revisited (2007). Pode ser uma instalação, com vários ambientes, onde o público efetivamente é parte da obra, como em Highway 101 (2000). Enfim, a gama de possibilidades é grande.

A percepção e resposta do público são desafiadas por todos esses elementos, desde a pesquisa corporal e seus estados cambiantes, passando pelo diálogo com os elementos extrínsecos à dança, pelo uso do ambiente em que a dança acontece e pelas próprias convenções de recepção do espetáculo. Por exemplo, em Appetite, Stuart decide deliberadamente não terminar o espetáculo, mas acender as luzes do teatro, que é uma convenção teatral de que o espetáculo terminou. Já em Highway 101, os diferentes espaços de cena e de saída propostos (sugerindo espaços de realidades diferentes) são combinados com diferentes modos de assistir, seja olhando para cima para uma cena que acontece em cima de um telhado de vidro, seja deitado sobre a barriga para ter a visão de baixo, etc.

Considerações finais

Ter entrado um pouco no mundo coreográfico desestabilizador (e fasci- 
nante) de Meg Stuart nos faz acreditar ainda mais na desestabilização como via de mudança e transformação, que é o que a desconstrução propõe. Acreditamos que sua contribuição é grande para nos percebermos em relação à contemporaneidade.

\section{Referências Bibliográficas}

ADSHEAD, Janet. (ed.). Dance analysis: theory and practice. Londres: Dance Books, 1988.

AYERS, Robert. "Meg Stuart: not really dance at all" In Dance Theatre Journal, vol.15, no 1, pp. 8-11, 1999.

BHABHA, Homi K. O Local da Cultura. Belo Horizonte: Ed. UFMG, 1998.

BURT, Ramsay. The male dancer. Londres: Routledge, 1995.

DERRIDA, Jacques. Gramatologia. São Paulo: Perspectiva, 2006.

Writing and Difference. Londres: Routledge, 2008.

FERNANDES, Ciane. O corpo em movimento: o sistema Laban/Bartenieff na formação e pesquisa em artes cênicas. 2aed. São Paulo: Annablume: 2006. . Pina Bausch e o Wuppertal Dança-Teatro: repetição e transformação. $2^{\text {a }}$ ed. São Paulo: Annablume, 2007.

FERNANDES, Ciane; MOURA, Rogério. “Des-Construindo Casas, Corpos e Cenas: Visitors Only, de Meg Stuart". In: Revista Digital Art\&, ano II, n. 01, abril 2004.

FOUCAULT, Michel. História da sexualidade I: a vontade de saber. Rio de Janeiro: Edições Graal, 1988.

GIL, José. Movimento total: o corpo e a dança. São Paulo: Iluminuras, 2004. LACERDA, Cláudio. Representações de Masculinidade na Dança e no Esporte: um Olhar sobre Nijinsky e Jeux. Recife: O Autor, 2010.

PEETERS, Jeroen (ed.). Are We Here Yet?: Damaged Goods Meg Stuart. Bélgica: Les Presses du Réel, 2010.

PERRONE-MOISÉS, Leyla. "Aquele Que Desprendeu a Ponta da Cadeia”. In NASCIMENTO, Evando (org.). Jacques Derrida: Pensar a Desconstrução. São Paulo: Estação Liberdade, 2005.

PRESTON-DUNLOP, Valerie. Looking at dances: a choreological perspective on choreography. Londres: Verve, 1998. SANCHEZ-COLBERG, Anna. "Altered States and Subliminal Spaces: Charting the Road Towards a Physical Theatre". In Performance Research 1(2), pp. 40-56. Londres: Routledge, 1996.

SCHLICHER, Susanne. "O Corpo Conceitual”. In Repertório Teatro \& Dança. Ano 4, n 5, 2001, pp. 30-36. Salvador: Universidade Federal da Bahia, Programa de Pós-Graduação em Artes Cênicas, 2001. 
